\title{
The relationship between distributed leadership and teachers' organizational commitment in Guangzhou city, China
}

\author{
Shoruok Mohammed Farag Mohammed Aboudahr and Liu Jiali \\ School of Education and Modern Languages University Utara, Malaysia \\ E-mails: shroukaboudaher@gmail.com, 335321811@qq.com
}

\section{ABSTRACT}

Since teachers and school leaders can establish cooperation and interaction to improve student performance, distributed leadership becomes a practical necessity of the education system. Study on distributed leadership is still in its infancy and needs to be improved. This study aimed to determine the relationship between distributed leadership and teachers' organizational commitment based on secondary schools in Baiyun district in Guangzhou city, China. This study conducted using the quantitative survey approach. The respondents for study, who comprised of 98 teachers, were selected through random sampling from 2 secondary schools. The data of the study has been collected by using 22 items of Distributed Leadership Inventory which was developed by Hulpia et al. (2009), and 15 items of Organizational Commitment Questionnaire (OCQ) which was developed by Mowday (1979). The data analysis using Descriptive Statistics, Independent Sample t-test, one-way ANOVA and Pearson correlation with SPSS version 22. According to the findings of the study, there were no differences between gender and teaching work experience towards organizational commitment. In addition, there was a positive relationship between school distributed leadership and teachers' organizational commitment. Besides, school principals' distributed leadership significantly predict teachers' organizational commitment. According to these findings, it is recommended that school leaders, in addition to sharing the clear vision, should also conduct decentralized leadership for teachers, regardless of gender or teaching work experience.

\section{Original Article}

PII: S232247701900001-9

Rec. 30 January 2019

Acc. 18 March 2019

Pub. 25 March 2019

\section{Keywords}

Distributed leadership

organizational

Commitment,

Support,

Supervision,

Leadership team,

Secondary school

teachers

\section{INTRODUCTION}

Education is an important tool for everyone to succeed in life and get different things. It helps to alleviate the challenges of life's difficult life. The knowledge gained throughout education made everyone feel confident in their lives. It offers a variety of opportunities to achieve a better life and thus promotes career development. The government has launched a number of campaigns to improve the value of education in the countryside. It brings equality to all people in society and promotes the development and development of the country (Power, 2014). Education plays also a vital role in the modern technological world. As a while, teachers play an important role in education. A good teacher helps us to become good citizens in society and good citizens in our country. Teachers know that students are the future of any country. Teacher development is the key to the development of the school and the premise of student development. Because the quality of teachers determines the quality of education, it is difficult for low-quality teachers to produce highquality students. It is impossible to achieve the scientific development of education without a team of teachers suitable for the development of the school (Block et al., 2012).

But teachers around the world now face problems such as job burnout, workload and turnover. Many schools are feeling the impact of this shift as teachers leave the industry faster and faster. In fact, research shows that $17 \%$ of new teachers leave the classroom in the first five years of teaching. According to Kena et al. (2015), this proportion has steadily increased by 3-5\% every year since 2008, making it a hot commodity for senior teachers (over 10 years). The workload of teachers refers to the tasks and time spent by teachers to complete 
professional roles. The research shows that teachers' working conditions have changed a lot in recent years. First, the teacher's task, the number of students they face, and the amount of time they have to control themselves. Second, teaching is more instrumental, expressive and effective, reducing the teaching satisfaction and professionalism (Lee et al., 2015).

After more than 20 years of reform and opening-up, China's society and economy have undergone tremendous changes. Although education has a certain lag in the superstructure, it is undergoing profound reform and development in order to adapt to the reform and development of the social economy. The adaptability of these macro backgrounds and teacher's education has undoubtedly become the basis and impetus for education teacher reform and development. Teacher occupation is a high - pressure profession. According to a Beijing-based survey conducted by the Institute of Basic Education of the Beijing Research Institute of Education, 93.1\% of people believe that teachers are becoming more and more difficult and stressful. $50.8 \%$ of the teachers said they would consider changing jobs if they thought they were organic. A joint survey conducted by the Shanghai Teacher Training Center, the Shanghai Mental Health Center and Shanghai Normal University showed that the detection rate of teacher's mental disorder is as high as $48 \%$. Of these, $12 \%$ had significant mental disorders, $2 \%$ were severe, symptoms were anxiety, depression, irritability, neurasthenia, and memory loss. Career stress is a double-edged sword (Bao \& Wang, 2012). Professional pressure on teachers' negative impact is mainly reflected in: first, mood disorders and mental health of teachers, often appear inexplicable anxiety, anxiety, depression, helpless, often angry, low self-efficacy, to the satisfaction and job burnout. Secondly, it leads to an increase in teachers' physical diseases. Studies show that constant stress can damage people's circulation and digestion, leading to diseases such as the heart, lungs, muscles and joints, and speed up the ageing process. Third, it leads to an increase in teacher negative behaviour: loss of control, insomnia, loss of appetite, smoking and alcohol abuse. The above three aspects are interrelated and influence each other, forming a vicious circle, which aggravates the psychological crisis of teachers, leading to many teachers teaching, changing jobs and retiring early (Wu \& Yu, 2014).

\section{Problem statement}

First, the teacher management system in China is in a critical situation. At present, China's teacher management is still dominated by economic contracts and regulations. In the personnel system, performance appraisal system, promotion system, salary management system, medical insurance system and a series of the system itself and the system implementation process, inevitably, is imperfect and unfair, unreasonable system lack problem. Only by gradually improving economic contracts and regulations can we solve these problems (Yao, 2011). Therefore, it is very easy for teachers to produce some unbalanced and unsatisfactory psychological states, which to some extent inhibits teachers' work enthusiasm and initiative, which is not conducive to improving teaching quality.

Secondly, teacher job burnout increases. Because school enrolment expansion in recent years, Chinese teachers with time is very short, it is difficult to keep up with the massive growth of students, teachers' workload has increased dramatically, many teachers teach several tasks at the same time, in order to ensure the quality will inevitably increase the pressure of work (Jiang, 2016), On the other hand, the reform of curriculum structure and content system, the rapid updating of modern teaching means and means, have put forward higher requirements for improving teachers' knowledge reserve and skills. At the same time, teachers must complete the scientific research tasks required by the school. In this long and heavy workload, teachers tend to cause job burnout among teachers. The emergence of job burnout has also led to teachers' enthusiasm for teachers, job insecurity and declining performance (Gao et al., 2014).

Third, the loss of teacher resources is serious. The flow of teacher resources can be divided into explicit loss and hidden loss. A clear loss is when a teacher leaves the job and moves to another school or workplace. Along with our country school personnel system reform and the implementation of the teachers' employment system, loss of teachers showed a one-way flow, the characteristics of the shift from economic less-developed areas to developed areas, focus on colleges and universities, colleges and universities for instance, university of traffic exacerbated the imbalance of education between regions (Zhao, 2010). The hidden loss manifests as the transfer of teachers' energy, 
neglecting their own work and paying more attention to the development of the second career. Teacher occupation and income is relatively stable, make the dominant loss relative to other professional college teachers is low, but due to the development of the market economy system and teachers face housing, income, and the cause of severe reality problem such as the recessive loss of teacher resources, the main performance on the job for less energy input, professional in the second, lack of initiative will update their teaching and scientific research task of knowledge and skills of a perfunctory response (Zeng \& Qi, 2013).

Fourthly, the construction of teacher ethics is flawed. In the process of China's transition from a planned economy to a market economy, due to the imperfect development of China's socialist market economy, the construction of social morality has had some negative effects. Market economy aims at maximizing profit. The principle of equal exchange is an unrestricted principle for all aspects of social life, and people's values are greatly affected. Individualism, hedonism, money worship, such as negative values also filled with the school, some teachers lack teaching, a tenured professor respectwork spirit, seriously affected the professional image of the teachers and students' physical and mental health (Imachukwu, 2014). In light of these problems, this study aims to explore the relationship between distributed leadership and teacher's organizational commitment. Therefore, the following are the research questions to be solved.

\section{Significance of the study}

The focus of this study is distributed leadership and teacher organization. A comprehensive analysis of their relationship will be conducted. These findings will provide new insights into the effective management of schools and teachers and will help teachers reduce stress. These findings are important not only to school principals and teachers but also to students. If the school principal changes its leadership style, the school will have a better culture and a freer learning environment. Better study for students.

From a theoretical perspective, organizational commitment research originates from enterprise management. Whether it is the basic source of theory or the scope of application, it is all about enterprise management. Foreign interest in teacher organization commitments has only begun in the past decade or so. Research into the group's commitment to Chinese teachers has just begun. With the deepening of the research, people are increasingly aware that in education, the human resources of teachers are more important than any other resources. Teacher's attitude and behaviour directly affect the effectiveness of education teaching (Xia \& Lee, 2014). On the other hand, scholars in education began to study the organizational commitment of teachers because of organizational commitment to predict psychological phenomena such as effort and turnover intention.

From the perspective of practice, the value of the school lies in cultivating and cultivating talents, exploring and discovering knowledge, serving and contributing to the society, inheriting and developing civilization. Therefore, the role of teacher organization in the process is crucial. First of all, the teacher's organizational commitment level is the best predictor of teacher resource turnover. Secondly, the high level of organizational commitment is the decisive factor for the stability of the school teachers and the guarantee of the stable development of the school. Thirdly, the level of teachers' organizational commitment is an important indicator to predict the achievement of school organizational goals and influence the performance of school organizational effectiveness. Fourthly, teachers' organizational commitment level will affect teachers' performance and promote the smooth development of school work. Fifth, it is conducive to the improvement of the school management system and teacher career planning and development. In addition, the study will narrow the gap between previous studies.

\section{Literature review}

Nowadays, many studies show that the leadership style of the principal is one of the most important factors to help school management succeed. Effective principals have indirect effects on school and student performance (not directly) because they shape the school's internal processes, climate, relationships and resources. According to Trakšelys et al. (2016), Leithwood and Mascall (2008) established effective principles to focus on the effective principles of the four core leadership practices; Set the direction, train the talent, redesign the organization, and improve the teaching plan. His research on the leadership style of the principal is the most important in transformational leadership, 
transactional leadership, teaching leadership and decentralized leadership. The study focused only on distributed leadership.

Distributed leadership is a new education leadership theory proposed in the 1990s. It is favoured by many scholars and experts. It is a leader, follower, and interactive network leadership practice in a given situation. According to Gronn (2000), the concept of "distributed leadership" first appeared in the social psychology literature of the early 1950s. So far, distributed leadership has not been defined precisely, but some scholars have made some useful explorations. According to Lakomski (2005) distributed leadership means leadership. Leadership is distributed in structured organizational relationships and expressed in the form of joint forces in the organization. In the Gronn (2002), distributed leadership offers a new commitment of "analysis unit", through the "analysis unit" can be from the overall sense of leadership, rather than simply as a collection of individual contributions. Distributed leadership is a leadership practice that involves leadership Shared across the organization, where leadership responsibilities are shared in related skills and expertise (Spillane et al., 2004).

More specifically, organizational commitment is composed of Mowbray (1994) defined, is composed of three parts: "the identity of the organization's goals and values, desire for the organization, as well as the organizational willingness to show effort." Similarly, Meyer and Allen, a three-component model is put forward, affective commitment is a want attached to the organization, continuance commitment is a people believe that they need to be attached to the organization and normative commitment is a people believe that they should be in the organization. These different types of commitments have different impacts on the organization's performance, and one person can show all of them. Organizational commitment is a state in which employees are committed to assisting in achieving organizational goals, as well as the level of identity, participation, and loyalty of employees. This is an emotional response that can be measured by people's behaviour, beliefs and attitudes, and can range from very low to very high.

\section{Theoretical framework}

Spillane (2006) pointed out that for the leader and their followers, distributed leadership as a practice has own situations, it consists of several separate activities. This leadership style related to social distribution, the functions of distributed leadership are extended to many individuals, leaders accomplished tasks through multiple interactions. As a while as Gronn (2000) defines distributed leadership as an emerging attribute of a population. At the same time, he also claims distributed leadership is a network interaction. Although Gronn and Spillane theoretically define distributed leadership, in empirical research it is still a nebulous concept, and relatively few studies attempt to measure it. One of the criticisms of research on Shared or distributed leadership is the lack of consensus on its definition.

Previous research has operationalized distributed leadership from two different perspectives. First, Leithwood and Mascall (2008) studied potential sources of influence, such as principals, regional managers, and teachers with designated leadership roles. The researchers investigated who was responsible for key leadership functions. Second, Pearce and Sims (2002) focused on the overall leadership team.

Therefore, in this study, the researchers distinguished distributed leadership into three dimensions, principals' support, principal's supervision and cohesive leadership team. According to Hulpia and Devos (2010) study in distributed leadership, a series of research and theory on the concept of organization function to the conceptualization, and members of what school is usually responsible for implementing these functions. In their research, they chose two main functions of the effective school leaders that were mentioned in the teaching and change leadership model, and the ones that were mentioned in the education revolution literature: supporting people, supervising teachers.

\section{Conceptual framework}

The research framework for the study is the relationship between distributed leadership and teacher's organizational commitment to a secondary school in China. The conceptual framework has one independent variable which includes five dimensions, gender, teaching work experience, support, supervision, and cooperation of the leadership team, while teacher's organizational commitment is the dependent variable. 


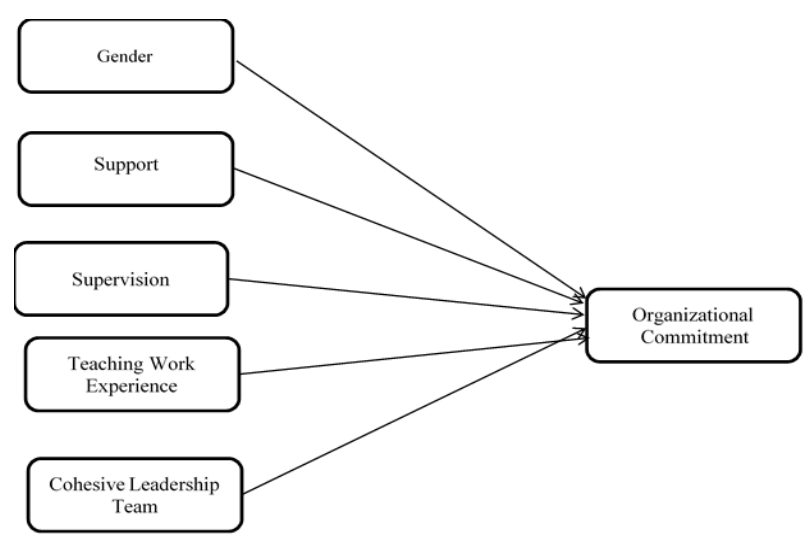

Figure 1. Developed by the Researcher, 2018.

\section{METHODOLOGY}

\section{Research design}

This research is focusing on the relationship between distributed leadership and teacher's organizational commitment. This study is quantitative in nature by using survey method to examine the relationship between independent and dependent variables. The analysis implemented to make sure the teacher who participated in the survey has a clear understanding of their principal's leadership style. The questionnaires consisted of three parts. Part one was designed to identify the demographic variables of respondents. Part two is distributed leadership inventory; the dimensions of distributed leadership were mainly measured by 22 items. Part three was designed to measure the Secondary Public-School teachers' organizational commitment. The questionnaire for Organizational Commitment was obtained by using the 15 items of Organizational Commitment Questionnaire (OCQ) which was developed by Mowday et al. (1979).

\section{Population}

The target population refers to the entire group which a researcher is interested in; the researcher wishes to conclusions by the group. As the objective is to examine the effect of distributed leadership on teachers' basic psychological needs satisfaction, therefore some selected secondary schools in China are the target population of this research study. The schools were chosen to be investigated by this study. Schools were chosen from the Baiyun districts in Guangzhou city. According to the Ministry of Education in China for 2016-2017, there are 896 teachers in Baiyun districts in Guangzhou city.

\section{Sample and sampling technique}

Choosing 98 teachers by using simple random sampling, questionnaires were distributed to these teachers. With the reference of Krejcie and Morgan's (1970) sample size table, the sample size of this study will be 98 teachers, comprised 22 (22.4\%) male teachers and $76(77.6 \%)$ female teachers.

\section{Research instrument}

To ensure the research is conducted effectively and efficiently, the detail of the procedures of obtaining information is needed in conducting the study in order to solve the problem. The quantitative research method was primarily used to obtain the information need for the purpose of the study. The questionnaires consisted of three parts. Part one was designed to identify the demographic variables of respondents by 2 items: gender and teaching work experience. Part two is Distributed Leadership Inventory. Distributed Leadership Inventory has been developed by Hulpia et al. (2009) with the purpose of determining teachers' perception levels of school principals' distributed leadership behaviours. Which include three dimensions: support, supervision, and cohesive leadership team. The dimensions of distributed leadership were mainly measured by 22 items.

Table 1. Test that has been used to treat study hypotheses

\begin{tabular}{lc} 
Hypotheses & \multicolumn{1}{c}{ Test } \\
$\begin{array}{l}\text { Ho (1): There are no significant differences between gender and organizational } \\
\text { commitment among secondary school teachers. }\end{array}$ & Independent Samples t-test \\
\hline
\end{tabular}

Ho (2): There are no significant differences between teaching work experiences and teachers organizational commitment.

ANOVA

Ho (3): There is no significant relationship between support and teachers organizational commitment.

Ho (4): There is no significant relationship between supervision and teachers organizational commitment.

Ho (5): There is no significant relationship between cohesive leadership team and teachers organizational commitment.
Pearson Correlation

Pearson Correlation

Pearson Correlation 


\section{RESULTS}

All data were analyzed using the statistical package of social science (SPSS version 22.0). Descriptive statistics, independent t-test, one-way ANOVA and Pearson correlation. According to table 2 research, the total of secondary school teachers involved in this study is 98 , comprised $22(22.4 \%)$ male teachers and $76(77.6 \%)$ female teachers. This presented the frequency of female teachers were more than male teachers.

\section{Secondary school teacher' based on Teaching Work Experiences}

As shown in Table 2 below, 68 (69.4\%) teachers had between 1-5 years of teaching work experience, 23 (23.5\%) teachers had between 6-10 years of teaching work experience. Also 7 (7.1\%) teachers had between 11-15 years of teaching work experience. Most of teaching work experience have had between 1-5 years in service.

Table 2 - Respondent's distribution based on gender

\begin{tabular}{lcc} 
Gender & Frequency & $\begin{array}{c}\text { Percentage } \\
(\%)\end{array}$ \\
\hline Male & 22 & 22.4 \\
Female & 76 & 77.6 \\
Total & 98 & 100
\end{tabular}

Table 3 The level of principals distributed leadership and organizational commitment.

\begin{tabular}{lcc} 
Variables & Mean & SD \\
\hline Principals' support & 3.42 & 0.73 \\
Principals' supervision & 3.80 & 0.74 \\
Cohesive leadership team & 3.43 & 0.71 \\
Teachers' organizational commitment & 2.98 & 0.34 \\
\hline
\end{tabular}

\section{Research findings based on research hypotheses}

As in earlier, there were two research questions that established six hypotheses in this current study. Therefore, this section displays the findings of hypotheses testing based on a relevant research question and research hypotheses.

\footnotetext{
The level of principals distributed leadership and organizational commitment

Based on the table, the secondary school principals' supervision shows the mean $(M=3.80$, $\mathrm{SD}=0.74$ ) of principals' supervision is very high followed by the mean $(M=3.43, S D=0.71)$ of cohesive leadership team, and the mean $(M=3.42, S D=0.73)$ of principals' support is very close to cohesive leadership team. In addition, the mean $(M=2.98$, $\mathrm{SD}=0.34$ ) of teachers' organizational commitment is very low. It means the level of teachers'
}

organizational commitment among these two secondary schools is very low.

\section{Differences between gender and teachers' organizational commitment \\ Based on table 4 Levene's Test was not} significant ( $>>0.05)$. The result shows that there is equal assumed between male and female secondary school teachers on organizational commitment. Therefore, Independent Sample t-test was statistically not significant (t $(96)=4.78, \mathrm{P}>0.05)$. This result failed to reject null hypothesis (Ho). There were no significant differences between male and female teachers on organizational commitment among secondary school teachers.

\section{Differences between teaching work experiences and teachers' organizational commitment}

Hypothesis $\mathrm{H} 2$ was tested using ANOVA. In the current study the mean difference and it is significant level was set at $\mathrm{P}<0.05$. In order to determine whether there is significant difference in teaching work experience on organizational commitment, one-way ANOVA is conducted.

Result in Table 5, shows that there are equal variances assumed between teaching work experience towards teachers' organizational commitment. The one-way ANOVA was not significant $F(2,95)=2.53, P>0.05)$ between teaching work experience towards teachers' organizational commitment. This result failed to reject null hypothesis (Ho). Hence, there were no significant differences between teaching work experiences and teacher's organizational commitment.

Relationship between principals' support and teachers' organizational commitment

Based on table 6 the finding indicates that the Pearson correlation was a positively significant relationship between support and teachers organizational commitment $(r=0.47, \mathrm{P}<0.01)$. High support from school principal in the school shows high teacher organizational commitment. While low support from school principle shows low teacher organizational commitment. There is a low positive relationship between principals' support and teachers' organizational commitment.

Relationship between Principals' Supervision and teachers' organizational commitment

Table 7 shows that there was a positive relationship between supervision and teachers organizational commitment $(\mathrm{r}=0.21, \mathrm{P}<0.05)$. It means high supervision shows high teachers organizational commitment and low supervision shows low 
teachers organizational commitment. There is a very low positive relationship between Principals' Supervision and Teachers Organizational Commitment.

Relationship between the cohesive leadership team and teachers' organizational commitment

According to table 8 the result implies that was a positive relationship between the cohesive leadership team and teachers, organizational commitment $(r=0.637, p<0.01)$. The school whose leadership team is more cohesive shows higher organizational commitment. On the contrary, the low cohesive leadership team shows low teachers' organizational commitment. There is a very moderate positive relationship between principals' supervision and teachers' organizational commitment.

Table 4. Independent $\mathrm{T}$-Test between Gender and Organizational Commitment.

$\begin{array}{lccccccc}\text { Gender } & \text { N } & \text { Mean } & \text { SD } & \text { df } & \text { t } & \text { p } \\ \text { Male } & 22 & 3.25 & 0.34 & 96 & 4.78 & 0.213 & - \\ \text { Female } & 76 & 2.91 & 0.29 & - & - & & -\end{array}$

Table 5. the one-way ANOVA between Teaching Work Experience on Organizational Commitment.

\begin{tabular}{|c|c|c|c|c|c|c|c|}
\hline Teaching work experience & $\mathbf{N}$ & Mean & SD & dfl & df2 & $\mathbf{F}$ & $\mathbf{p}$ \\
\hline $1-5$ & 68 & 2.94 & 0.35 & 2 & 95 & 2.53 & 0.08 \\
\hline $6-10$ & 23 & 3.08 & 0.26 & & & & \\
\hline $11-15$ & 7 & 3.15 & 0.27 & & & & \\
\hline
\end{tabular}

Table 6. The Relationship between Principals' Support and Teachers Organizational Commitment.

$\begin{array}{lc}\text { Independent variable } & \text { Teachers Organizational Commitment. } \\ \text { Support } & 0.467^{* *}\end{array}$

Table 7. The relationship between Principals' Supervision and Teachers Organizational Commitment. Independent variable Supervision Teachers Organizational Commitment $0.21^{*}$

Table 8. The relationship between Cohesive Leadership Team and Teachers Organizational Commitment. Independent variable cohesive leadership team Teachers Organizational Commitment $0.637^{* *}$

\section{RESULTS AND DISCUSSION}

\section{Discussion of findings based on the research question}

The discussion in this chapter examined the three research questions of the current study. Based on the result of the hypothesis and findings. Also, the findings were compared with similar researches in the literature reviewed.

\section{The level of principals' distributed leadership} and teachers' organizational

The results show that the level of principal's distributed leadership in secondary schools is moderate. But the level of organizational commitment among teachers is very low. It means this schools' principals have a moderate level of leadership but the teachers in these school feel not committed. This result is in line with study of Chen (2010), the distributed leadership among school principals in Ningxia province is at a moderate level and also the teachers feel low commitment.

\begin{abstract}
Gender on teachers' organizational commitment

In this study, the organizational commitment among male and female teachers have no differences. The male teachers and the female teachers have the same perceptive on commitment in Guangzhou city. This study concurred with finding of Voloshin (2016).

Teaching work experience on teachers' organizational commitment

The result indicated that teaching work experience will not influence the teachers' perception of organizational commitment among these two schools in Guangzhou city, China. The result concurred with finding (Gholipour et al., 2012), the finding also shows there was no significant correlation between teacher's organizational commitment and organizational work experience in Tehran province, Iran. On the opposite, Lee (2016) stated there were significantly different in teaching working experience in Shenzhen city, China.
\end{abstract}




\section{Principals' support on teachers organizational commitment}

In current study, the support of school principals has a low level in Guangzhou city. But the support from principals also will influence teachers' organizational commitment. The more support from principals the more commitment teachers felt. The result concurred with finding Hulpia et al. (2010). Compared with supervision the number of principals' support for teacher's organizational commitment is more important in Belgium. This study is support of the research by Akdemir and Ayik (2017), supervision is one of the sub-dimensions of distributed leadership behaviour and organizational commitment of school principals, and there is a low \positive and significant relationship between them in secondary schools of Erzurum in Turkey.

\section{Cohesive leadership team on teachers organizational commitment}

The result shows when the leadership team of schools are more cohesive the organizational commitment among teachers will increase. Otherwise, if the school leadership team did not work well the teacher will have low organizational commitment to school. This study is support of the research by Akdemir and Ahmet (2017) in Turkey, there was a positive and significant relationship between leadership team and, which is one of the sub-dimensions of the distributed leadership behaviour and organizational commitment of school principal.

\section{Implications}

This paper proposes some suggestions to improving the level of teachers' organizational commitment, which can be discussed by theoretical researchers and practical operators

\section{CONCLUSION}

This study was an effort to examine the difference between gender and teaching work experience among secondary school on teachers' organizational commitment in Guangzhou city, China. The result shows that there are no significant differences between male and female toward organizational commitment. while there were no significant differences between teaching work experience and organizational commitment. In additional this study aimed to determine the relationship between three dimensions of distributed leadership on teacher organizational commitment in Guangzhou city, China. The current study implies that distributed leadership had positively related to organizational commitment.

\section{Future research}

This study is only limited to research in secondary school. Therefore, the data and results are only applicable to research in a secondary school in Guangzhou city. School in different area have different characteristics, the characteristics of teachers' organizational commitment also have bigger difference. Therefore, it is also meaningful to compare the differences between teachers' organizational commitment in different regions.

\section{H REFERENCES}

Akdemir, O. R., \& Ayik, A. (2017). The Impact of Distributed Leadership Behaviors of School Principals on the Organizational Commitment of Teachers.Universal Journal of Educational Research, 5(n12B), 18-26. Google Scholar ; https://eric.ed.gov/?id=EJ1165487

Bao, W., \& Wang, J. Y. (2012). Empirical research on occupational stress and academic output of Chinese university teachers. Peking University Education Review, 10(1), 124-191.

Block, E., Crochet, F., Jones, L., \& Papa, T. (2012). The Importance of Teacher's Effectiveness. Creative Education, 3, 380-401. Google Scholar ; http://dx.doi.org/10.4236/ce.2012.326173

Gao, X. A., Liao, Y., \& Li, Y. (2014). Empirical studies on foreign language learning and teaching in China (2008-2011): A review of selected research. Language Teaching, 47(1), 56-79. Google Scholar ;

Gronn, P. (2000). Distributed properties: A new architecture for leadership. Educational Management Administration Leadership, 28(3), 317-338. Google Scholar ; https://doi.org/10.1177/0263211X000283006

Hulpia, H., \& Devos, G. (2010). How distributed leadership can make a difference in teachers' organizational commitment? A qualitative study. Teaching and teacher education, 26(3), 565-575. Google Scholar ; https://doi.org/10.1016/j.tate.2009.08.006

Hulpia, H., Devos, G., \& Rosseel, Y. (2009). The relationship between the perception of distributed leadership in secondary schools and teachers' and teacher leaders' job satisfaction and organizational commitment. School Effectiveness and School Improvement, 20(3), 291-317. https://doi.org/10.1080/09243450902909840; Google Scholar

Imachukwu, O. T. (2014). Exploring perspectives of cultural differences in the workplace (Doctoral dissertation, Walden University). Google Scholar ; https://search.proquest.com/docview/1509124938?pqorigsite=gscholar \&fromopenview=true

Jiang, J. (2016). On the pressure problem of young teachers in colleges and universities and their countermeasures. Journal of Henan University, 56(1), 123-130. 
Kena, G., Musu-Gillette, L., Robinson, J., Wang, X., Rathbun, A., Zhang, J., ... \& Velez, E. D. V. (2015). The Condition of Education 2015. NCES 2015-144. National Center for Education Statistics. Google Scholar ; https://eric.ed.gov/?id=ED556901

Krejcie, R. V., \& Morgan, D. W. (1970). Determining sample size for research activities. Educational and Psychological Measurement, 30, 607-610. Google Scholar ; https://doi.org/10.1177/001316447003000308

Lakomski, G. (2005). Managing without Leadership: Towards a Theory of Organizational Functioning. Amsterdam: Elsevier. Google Scholar

Lee, Y. Z. (2016). Research on the status quo and influencing factors of the organizational commitment of middle school teachers. Teaching \& Administration, 6, 19-23.

Leithwood, K., \& Mascall, B. (2008). Collective leadership effects on student achievement. Educational Administration Quarterly, 44(4), 529-561. Google Scholar ; https://doi.org/10.1177/0013161X08321221

Mowbray, D. (1994). A Generalised Model of Organizational Design and Development, A pamphlet. Chemtenham: MAS. Google Scholar

Mowday, R. T., Steers, R. M., \& Porter, L. W. (1979). The Measurement of Organizational Commitment. Journal of Vocational Behavior, 14, 224-247. Google Scholar ; https://doi.org/10.1016/0001-8791(79)90072-1

Pearce, C. L., \& Sims, H. P. (2002). Vertical versus shared leadership as predictors of the effectiveness of change management teams: An examination of aversive, directive, transactional, transformational and empowering leader behaviors. Group Dynamics: Theory, Research, and Practice, 6(2), 172-197. Google Scholar ; https://doi.org/10.1037/1089-2699.6.2.172
Power, C. O. L. I. N., \& Sophister, J. (2008). Education Development: Importance, Challanges and Solutions. The Stundent Economic Review, 28, 149-155. Google Scholar

Spillane, J. (2006). Distributed Leadership, Jossey-Bass, San Francisco, CA. Google Scholar

Spillane, J. P., Halverson, R., \& Diamond, J. B. (2004). Towards a theory of leadership practice: A distributed perspective. Journal of curriculum studies, 36(1), 3-34. Google Scholar

Trakšelys, M., Melnikova, J., \& Martišauskienè, D. (2016). Competence of the leadership influence school improvement. Andragogika, 1(7), 78-108. http://dx.doi.org/10.15181/andragogy.v7io.1379; Google $\underline{\text { Scholar }}$

Voloshin, G. V. (2016). Differences in Organizational Commitment Between Male and Female Coaches at the High School Level. Education Doctoral, 270-385. https://fisherpub.sjfc.edu/education etd/270/ Google $\underline{\text { Scholar }}$

Wu, W. C., \& Yu, J. L. (2014). New teachers pressure source research. Teaching and Management, $11,80-83$.

Xia, J., \& Lee, C. X. (2014). Recent research progress on teachers' organizational commitment in China and abroad. Contemporary Teacher Education, 1, 44-48.

Yao, S. Y. (2011). Discussion on the mode of "employee assistance program" of teacher stress management. Education Research Monthly, 6, 64-66.

Zeng, X. J., \& Qi, F. (2013). Investigation on the current situation of teachers' work pressure in colleges and universities and their management countermeasures. Modern Education Management, 8, 72-77.

Zhao, J. L. (2010). Analysis and mitigation strategies of rural primary school teachers under the background of new curriculum. Education Exploration, 12, 111-113. 